\title{
Analysis of National Trends in Admissions (1) crossanat for Pulmonary Embolism
}

\author{
Sean B. Smith, MD; Jeffrey B. Geske, MD; Parul Kathuria, BA; Michael Cuttica, MD; Daniel R. Schimmel, MD; \\ D. Mark Courtney, MD; Grant W. Waterer, MD; and Richard G. Wunderink, MD
}

BACKGROUND: Pulmonary embolism (PE) remains a significant cause of hospital admission and health-care costs. Estimates of PE incidence came from the 1990s, and data are limited to describe trends in hospital admissions for PE over the past decade.

METHODS: We analyzed Nationwide Inpatient Sample data from 1993 to 2012 to identify patients admitted with PE. We included admissions with International Classification of Diseases, 9th revision, codes listing PE as the principal diagnosis as well as admissions with PE listed secondary to principal diagnoses of respiratory failure or DVT. Massive PE was defined by mechanical ventilation, vasopressors, or nonseptic shock. Outcomes included hospital lengths of stay, adjusted charges, and all-cause hospital mortality. Linear regression was used to analyze changes over time.

RESULTS: Admissions for PE increased from 23 per 100,000 in 1993 to 65 per 100,000 in 2012 $(P<.001)$. The percent of admissions meeting criteria for massive PE decreased $(5.3 \%$ to $4.4 \%, P=.002$ ), but the absolute number of admissions for massive PE increased (from 1.5 to 2.8 per $100,000, P<.001)$. Median length of stay decreased from 8 (interquartile range [IQR], $6-11)$ to 4 (IQR, 3-6) days $(P<.001)$. Adjusted hospital charges increased from $\$ 16,475$ (IQR, \$10,748-\$26,211) in 1993 to \$25,728 (IQR, \$15,505-\$44,493) in $2012(P<.001)$. All-cause hospital mortality decreased from $7.1 \%$ to $3.2 \%(P<.001)$, but population-adjusted deaths during admission for PE increased from 1.6 to 2.1 per 100,000 $(P<.001)$.

CONCLUSIONS: Total admissions and hospital charges for PE have increased over the past two decades. However, the population-adjusted admission rate has increased disproportionately to the incidence of patients with severe PE. We hypothesize that these findings reflect a concerning national movement toward more admissions of less severe PE.

CHEST 2016; 150(1):35-45

KEY WORDS: hospitalization; mortality; pulmonary embolism

ABBREVIATIONS: AHRQ $=$ Agency for Healthcare Research and Quality; CTA = CT angiography; HCUP = Healthcare Cost and Utilization Project; ICD-9 = International Classification of Diseases, 9th revision; IQR = interquartile range; IVC = inferior vena cava; $\mathrm{LOS}=$ length of stay; NIS = Nationwide Inpatient Sample; PE = pulmonary embolism

AfFiliations: Division of Pulmonary and Critical Care Medicine (Drs Smith, Cuttica, Waterer, and Wunderink; and Ms Kathuria), Department of Medicine, Feinberg School of Medicine, Northwestern University, Chicago, IL; Division of Cardiovascular Disease (Dr Geske), Department of Medicine, Mayo Clinic, Rochester, MN; Division of Cardiovascular Disease (Dr Schimmel), Department of Medicine, Feinberg School of Medicine, Northwestern University, Chicago, IL; Department of Emergency Medicine (Dr Courtney), Feinberg School of Medicine, Northwestern University, Chicago, IL; and University of Western Australia (Dr Waterer), Perth, Australia.
FUNDING/SUPPORT: S. B. S. was supported by a National Institutes of Health/National Heart, Lung, and Blood Institute (Training Grant T32HL076139). R. G. W. is supported in part by the Centers for Disease Control and Prevention (Grant 1U18IP000490 "Incidence and Etiology of Influenza-Associated Community-Acquired Pneumonia in Hospitalized Persons Study"). G. W. W. is partially supported by the National Health and Medical Research Council of Australia.

CORRESPONDENCE TO: Sean B. Smith, MD, Pulmonary and Critical Care Medicine, Feinberg School of Medicine, Northwestern University, 660 N Westmoreland Rd, Lake Forest, IL 60045; e-mail: sean@ northwestern.edu

Copyright () 2016 American College of Chest Physicians. Published by Elsevier Inc. All rights reserved.

DoI: http://dx.doi.org/10.1016/j.chest.2016.02.638 
Pulmonary embolism (PE) is a common condition with significant morbidity and mortality, often requiring hospital admission. ${ }^{1}$ The overall incidence of $\mathrm{PE}$ in the general population was reported at 69 per 100,000 in $1998 .^{2}$ Since that estimate, significant changes in PE management have occurred, including trends toward more (and higher quality) CT angiography (CTA) studies, more sensitive D-dimer assays, and new treatment options, including low-molecular heparins and new oral anticoagulants. Given these changes and increasing financial pressures to limit hospital costs, we hypothesized that the incidence and outcomes of patients hospitalized with PE may also have evolved.
The Nationwide Inpatient Sample (NIS) is a weighted sample of hospital admission data prepared by the Healthcare Cost and Utilization Project (HCUP) from the Agency for Healthcare Research and Quality (AHRQ). The NIS provides data from US admissions since the 1990s, accounting for approximately $20 \%$ of US hospital discharges, with a weighted estimate of $36,484,846$ admissions from 4,378 hospitals in 44 states in 2012. Several prior studies have used NIS to study PE, including an analysis that demonstrated increased PE hospitalizations following the increased usage of CTA in the late 1990s. ${ }^{3-6}$

\section{Methods}

We performed an analysis of NIS data to consider the trends in hospitalization for PE from 1993 to 2012. International Classification of Diseases, 9th revision (ICD-9) coding was used to identify patients who were admitted with PE. ICD-9 code 415 (acute pulmonary heart disease) was considered for selection of patients (Table 1). Patients with codes 415.1, 415.13, and 415.19 were included. ${ }^{7}$ We excluded codes for acute cor pulmonale (415.0), iatrogenic PE (415.11), septic PE (415.12), and those for PE secondary to obstetrical complications (673.xx). The purpose of these criteria was to describe the incidence of $\mathrm{PE}$ as its own de novo thromboembolic condition. Acute cor pulmonale was excluded because it was believed this condition was unlikely to be related solely to acute PE. Beginning in 1998, NIS provided both principal and secondary diagnoses. We included admissions with a principal diagnosis of $\mathrm{PE}$ and those with a secondary diagnosis of $\mathrm{PE}$ if the principal diagnosis was either respiratory failure $(518.81,518.82,518.84,799.1)$ or DVT $(453.4,453.40$, 453.41, 453.42, 453.8, 453.82, 453.83, 453.9) (Table 1). Admissions were reported per 100,000 population based upon US census data. ${ }^{8}$

Demographics included age, sex, and self-identified race. We considered the following comorbidity data that were provided by AHRQ from 2002 to 2012: diabetes mellitus; obesity; renal failure; chronic lung disease; liver disease; coagulopathy; heart failure; hypertension; chronic neurologic disease; paralysis; peripheral vascular disease; and valvular heart disease. The following AHRQ comorbidities were unified into a composite comorbidity of malignancy: lymphoma; solitary tumor; and metastatic cancer. We determined the number of admissions that had pulmonary arteriograms based upon ICD-9 procedure code 88.43.

Primary outcomes included all-cause hospital mortality, length of stay (LOS), and hospital charges. Charges were adjusted for 2012 dollars with consumer price indices for each year. ${ }^{9}$ Secondary outcomes included the need for mechanical ventilation (procedure codes 96.70, $96.71,96.72)$, thrombolytic therapy $(99.10)$, or inferior vena cava (IVC) filter placement (38.7). Massive PE was defined by the documentation of mechanical ventilation, vasopressors (procedure code 00.17), or nonseptic shock (diagnosis codes 785.50, 785.51, 785.59). Because of the availability and number of codes provided in

TABLE 1] ICD-9 Codes for Acute Pulmonary Heart Disease

\begin{tabular}{|c|c|}
\hline Inclusion & Exclusion \\
\hline $\begin{array}{l}\text { 415.1 PE and infarction } \\
415.13 \text { Saddle embolus of pulmonary artery } \\
415.19 \text { Other PE }\end{array}$ & $\begin{array}{l}\text { 415.0 Acute cor pulmonale } \\
\text { 415.11 Iatrogenic PE and infarction } \\
415.12 \text { Septic PE } \\
\text { 416.xx Chronic pulmonary heart disease } \\
634.6,639.6,673 . x x \text { PE complicating abortion, molar } \\
\text { pregnancies, pregnancy, or childbirth } \\
\text { V12.55 Personal history of PE }\end{array}$ \\
\hline $\begin{array}{l}\text { Other principal diagnoses included if PE was } \\
\text { listed as a secondary diagnosis } \\
518.81 \text { Acute respiratory failure } \\
\text { 518.82 Other pulmonary insufficiency } \\
\text { 518.84 Acute and chronic respiratory failure } \\
\text { 799.1 Respiratory arrest } \\
\text { 453.4x Acute DVT of lower extremities } \\
\text { 453.8 Acute DVT of other specified veins } \\
\text { 453.82 Acute DVT of upper extremities } \\
\text { 453.83 Acute DVT of upper extremities NOS } \\
\text { 453.9 Other DVT of unspecified site }\end{array}$ & \\
\hline
\end{tabular}

ICD = International Classification of Diseases, 9th revision; NOS = not otherwise specified; PE = pulmonary embolism. 
NIS, our analyses of massive PE, thrombolytic therapy, and DVT were limited to the years from 1998 to 2012 .

Statistical analyses were performed with Stata 13.0. Not all continuous data were normally distributed, and so median values with interquartile ranges (IQR) were reported. Linear regression was used to analyze data over the independent variable of time ( $r^{2}$ values are reported), and
Breusch-Pagan testing was used to assess for heteroscedasticity after 1998 when principal and secondary diagnoses were included. Student $t$ tests were used to compare groups. Statistical significance was defined as $P<.05$. This study was deemed exempt by our institutional review board because NIS is a public database in which all data are publically available and deidentified. All authors participated in NIS data training per HCUP policies.

\section{Results}

\section{Admissions}

The number of admissions for PE increased from $59,963$ (23 per 100,000$)$ in 1993 to 202,015 (65 per $100,000)$ in $2012\left(r^{2}=0.96, P<.001\right)$ (Table 2, Fig 1$)$. This represented a $237 \%$ increase, whereas the population size increased by only $20 \%$. Median age in 1993 was 68 (IQR, 54-77) and 65 (IQR, 51-77) years in $2012\left(r^{2}=0.85, P<.001\right)$. The proportion of male patients increased from $44.9 \%$ in 1993 to $47.3 \%$ in 2012 $\left(r^{2}=0.47 ; P<.001\right)$. The majority of patients were white $\left(62.1 \%\right.$ in $1993,70.2 \%$ in $2012 ; r^{2}<0.01$, $P=.932)$, whereas the frequency of other race/ ethnicities, including black (8.0\% in $1993,15.9 \%$ in 2012; $r^{2}=0.66, P<.001$ ), significantly increased. Pulmonary arteriography was documented in $2.8 \%$ of all cases, and the incidence decreased from $4.1 \%$ of admissions in 1993 to $1.5 \%$ in $2012\left(r^{2}=0.70\right.$, $P<.001)$. The percent of admissions of patients with concurrent DVT remained stable $38.0 \%$ in 1998 ; $36.3 \%$ in $\left.2012 ; r^{2}=0.09, P=.282\right)$.

After 1998, there was an increasing proportion of admissions for which PE was listed secondary to a principal diagnosis of DVT or respiratory failure: $7.1 \%$ to $14.3 \%\left(r^{2}=0.91, P<.001\right)$. During this period, however, the absolute number of admissions with PE as either a principal or secondary diagnosis still increased: 25.8 to 55.3 per 100,000 for principal diagnoses $\left(r^{2}=0.95, P<.001\right)$ and 2.0 to $9.2 \mathrm{per}$ 100,000 for secondary diagnoses $\left(r^{2}=0.89, P<.001\right)$. Breusch-Pagan testing of a multiple linear regression model for principal and secondary diagnoses after 1998 suggested no significant heteroscedasticity $\left(\chi^{2} 0.06\right.$, $P=.805)$, suggesting that the overall trend was still primarily related to an increase in principal diagnoses.

\section{Comorbidities}

From 2002 to 2012, the percent of admissions of patients with diabetes, hypertension, obesity, liver disease, coagulopathy, renal failure, neurologic disease, or peripheral vascular disease all significantly increased (Table 3). A nonsignificant downward trend was observed in the percent of admissions with malignancy (20.9\% to $\left.14.5 \%, r^{2}=0.30, P=.08\right)$.

\section{Outcomes}

All-cause, overall hospital mortality was $5.1 \%$, which decreased from $7.1 \%$ in 1993 to $3.2 \%$ in $2012\left(r^{2}=0.93\right.$, $P<.001$ ) (Table 4). However, the total number of patients who died increased from 1.6 to 2.1 per 100,000 population $\left(r^{2}=0.63, P<.001\right.$; Fig 2$)$. Overall mortality was higher for massive PE compared with nonmassive PE: $44.0 \%$ vs $2.7 \%, P<.001$. Mortality rates significantly decreased over time in both massive and nonmassive PE $(P<.001)$. Median LOS was 8 (IQR, 6-11) days in 1993 and 4 (IQR, 3-6) days in $2012\left(r^{2}=0.86, P<.001\right)$. The percent of admissions requiring mechanical ventilation decreased from $4.9 \%$ in 1998 to $3.7 \%$ in $2012\left(r^{2}=0.69, P<.001\right)$. The percent of admissions that met criteria for massive PE decreased from $5.3 \%$ in 1998 to $4.4 \%$ in $2012\left(r^{2}=0.54, P=.002\right)$, but the absolute number of massive PE admissions increased from 1.5 to 2.8 per 100,000 population $\left(r^{2}=0.93, P<.001\right)$.

The overall incidence of IVC filter placement increased from $9.0 \%$ in 1993 to $11.4 \%$ in $2012\left(r^{2}=0.336\right.$, $P=.007)$, although the incidence steadily decreased from $15.2 \%$ in 2006 to $11.4 \%$ in 2012 . For the years 1998 to 2012, IVC filter placement was more common in massive compared with nonmassive PE (21.3\% vs $12.4 \%, P<.001)$. Thrombolytic therapy increased from $0.3 \%$ of the admissions in 1998 to $2.4 \%$ in 2012 $\left(r^{2}=0.62, P<.001\right)$. Similar increases in thrombolytic therapy were observed in both nonmassive and massive $\mathrm{PE}$, although thrombolytic therapy was more prevalent in massive compared with nonmassive PE: $8.3 \%$ vs $1.5 \%(P<.001)$.

Despite a shorter median LOS, median adjusted hospital charges increased by $162 \%$ : from $\$ 16,475$ (IQR, $\$ 10,748-\$ 26,211$ ) in 1993 to $\$ 25,728$ (IQR, $\$ 15,505$ $\$ 44,493)$ in $2012\left(r^{2}=0.94, P<.001\right)$ (Table 4; Fig 3). Given the mean charges of $\$ 39,330$ for an estimated 202,015 admissions in 2012, we estimate a national bill of $\$ 7.9$ billion for PE admissions in 2012 compared with an adjusted estimated bill of \$1.4 billion in 1993 . 
TABLE 2 ] Admissions and Demographics for Patients Hospitalized With PE From 1993 to 2012

\begin{tabular}{|c|c|c|c|c|c|c|c|c|c|c|c|c|c|c|}
\hline Year & PE Admissions & $\begin{array}{c}\text { Admissions } \\
\text { per } \\
100,000\end{array}$ & $\begin{array}{c}\text { Admissions } \\
\text { With PE as } \\
\text { Principal } \\
\text { Diagnosis, } \\
\%\end{array}$ & $\begin{array}{l}\text { Median } \\
\text { Age, y }\end{array}$ & IQR & $\begin{array}{c}\text { Male, } \\
\%\end{array}$ & White, \% & Black, \% & $\begin{array}{c}\text { Other } \\
\text { Race, \% }\end{array}$ & $\begin{array}{l}\text { Race Not } \\
\text { Listed, } \\
\%\end{array}$ & DVT, \% & $\begin{array}{l}\text { Massive } \\
P E, \%\end{array}$ & $\begin{array}{l}\text { Massive } \\
\text { PE per } \\
100,000\end{array}$ & $\begin{array}{c}\text { Pulmonary } \\
\text { Angiography, } \\
\%\end{array}$ \\
\hline 1993 & 59,963 & 23 & 100.0 & 68 & $54-77$ & 44.9 & 62.1 & 8.0 & 3.7 & 25.9 & & & & 4.1 \\
\hline 1994 & 64,397 & 24 & 100.0 & 68 & $54-77$ & 44.2 & 63.9 & 9.2 & 3.5 & 23.4 & & & & 3.8 \\
\hline 1995 & 70,330 & 26 & 100.0 & 68 & $53-77$ & 43.4 & 66.3 & 10.7 & 3.6 & 19.8 & & & & 3.9 \\
\hline 1996 & 70,594 & 26 & 100.0 & 68 & $54-77$ & 43.2 & 65.1 & 10.4 & 3.6 & 20.7 & & & & 3.9 \\
\hline 1997 & 68,060 & 25 & 100.0 & 68 & $53-77$ & 41.8 & 64.2 & 10.4 & 4.4 & 21.5 & & & & 4.4 \\
\hline 1998 & 76,503 & 28 & 92.9 & 68 & $53-77$ & 41.6 & 62.2 & 9.0 & 3.9 & 25.1 & 38.0 & 5.3 & 1.5 & 5.7 \\
\hline 1999 & 81,285 & 29 & 92.7 & 67 & $52-77$ & 41.4 & 62.4 & 10.1 & 4.2 & 23.3 & 37.4 & 5.4 & 1.6 & 5.3 \\
\hline 2000 & 86,788 & 31 & 92.8 & 67 & $52-77$ & 41.4 & 61.6 & 9.5 & 5.0 & 24.0 & 38.2 & 4.7 & 1.4 & 3.8 \\
\hline 2001 & 98,133 & 34 & 92.7 & 67 & $52-77$ & 41.0 & 57.1 & 9.3 & 4.7 & 28.9 & 39.2 & 5.0 & 1.7 & 3.6 \\
\hline 2002 & 110,746 & 39 & 92.7 & 66 & $51-77$ & 41.6 & 54.1 & 10.5 & 5.0 & 30.3 & 40.2 & 4.8 & 1.9 & 3.7 \\
\hline 2003 & 120,891 & 42 & 92.4 & 65 & $50-77$ & 42.4 & 54.5 & 10.8 & 5.7 & 29.1 & 39.3 & 4.8 & 2.0 & 3.1 \\
\hline 2004 & 127,267 & 43 & 92.6 & 65 & $50-77$ & 43.8 & 54.4 & 11.1 & 5.2 & 29.1 & 38.7 & 4.9 & 2.1 & 3.3 \\
\hline 2005 & 139,751 & 47 & 91.1 & 65 & $50-77$ & 44.7 & 56.9 & 9.3 & 5.6 & 28.1 & 38.9 & 4.9 & 2.3 & 3.0 \\
\hline 2006 & 157,362 & 53 & 90.0 & 65 & $51-77$ & 45.0 & 55.1 & 10.7 & 6.0 & 28.3 & 39.3 & 5.1 & 2.7 & 2.7 \\
\hline 2007 & 164,690 & 55 & 88.8 & 65 & $50-77$ & 45.8 & 53.2 & 11.8 & 6.2 & 28.7 & 38.9 & 4.7 & 2.6 & 3.0 \\
\hline 2008 & 185,021 & 61 & 85.0 & 65 & $50-77$ & 46.5 & 60.7 & 11.7 & 7.0 & 20.5 & 39.3 & 4.7 & 2.9 & 2.3 \\
\hline 2009 & 190,747 & 62 & 84.3 & 63 & $50-76$ & 47.1 & 64.0 & 12.6 & 7.7 & 15.8 & 39.3 & 4.8 & 3.0 & 1.6 \\
\hline 2010 & 201,944 & 65 & 85.0 & 63 & $50-76$ & 47.4 & 65.5 & 15.8 & 7.0 & 11.5 & 37.1 & 4.7 & 3.1 & 1.4 \\
\hline 2011 & 211,527 & 68 & 84.8 & 64 & $51-77$ & 47.2 & 66.9 & 15.1 & 7.9 & 9.9 & 37.3 & 4.7 & 3.2 & 1.2 \\
\hline 2012 & 202,015 & 65 & 85.7 & 65 & $51-77$ & 47.3 & 70.2 & 15.9 & 8.4 & 5.5 & 36.3 & 4.4 & 2.8 & 1.5 \\
\hline Overall & $2,488,012$ & & 90.1 & 66 & $51-77$ & 44.8 & 61.1 & 11.9 & 6.0 & 21.0 & 33.3 & 4.8 & & 2.8 \\
\hline$P$ value & $<.001$ & $<.001$ & $<.001$ & $<.001$ & & $<.001$ & .932 & $<.001$ & $<.001$ & .041 & .282 & .002 & $<.001$ & $<.001$ \\
\hline$r^{2}$ & 0.957 & 0.955 & 0.905 & 0.851 & & 0.471 & 0.000 & 0.656 & 0.933 & 0.211 & 0.088 & 0.535 & 0.932 & 0.702 \\
\hline
\end{tabular}

IQR = interquartile range. See Table 1 legend for expansion of other abbreviation. 


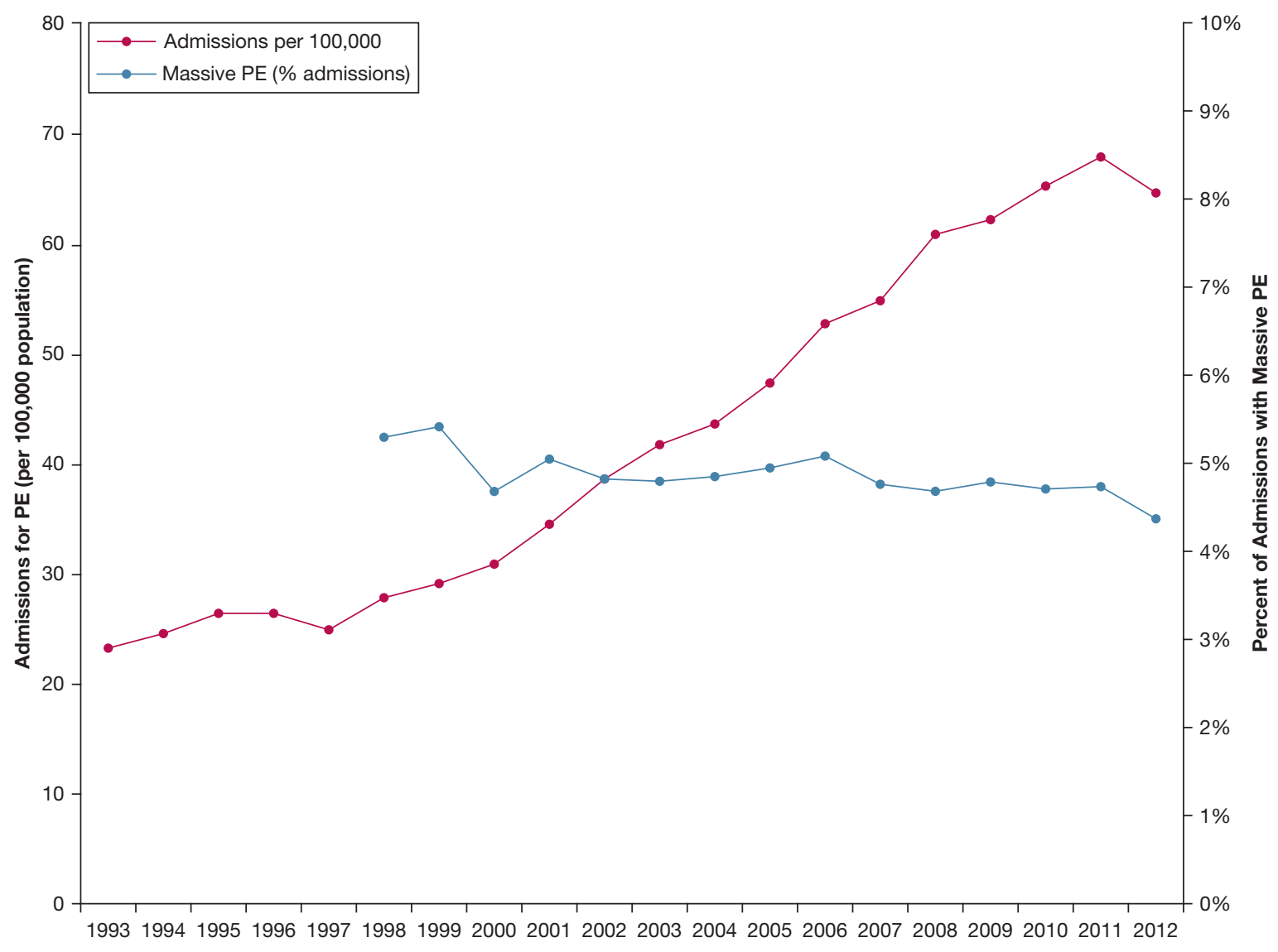

Figure 1 - Patients hospitalized for PE from 1993 to 2012. The number of admissions for PE significantly increased; however, the percentage of admissions that met criteria for massive PE decreased. $P E=$ pulmonary embolism.

\section{Discussion}

This study is the largest longitudinal analysis of PE admissions in the NIS database, allowing for descriptions of PE trends over 20 years. We found that population-adjusted admissions for PE increased from 23 to 65 per 100,000 from 1993 to 2012. Although there was a significant increase in the proportion of admissions in which PE was listed as a secondary diagnosis after 1998, the lack of heteroscedasticity in the regression analysis suggests that the overall increase was not solely from a change in our inclusion criteria after 1998. Indeed, the majority of admissions after 1998 continued to list PE as the principal diagnosis. Although the absolute population-adjusted number of massive PE increased, the proportion of admissions that met criteria for massive PE significantly decreased. Likewise, the absolute population-adjusted number of patients who died increased, but hospital mortality rates decreased. Per-patient hospital charges markedly increased, despite decreased hospital LOS.

Although our study is limited to PE patients who were hospitalized, our data are consistent with previous reports regarding overall PE incidence. Silverstein et $\mathrm{al}^{2}$ estimated PE incidence (outpatient or inpatient) to be 69 per 100,000 in a cohort study of 2,218 patients in Olmsted County, MN, from 1966 to 1990. Results from a Canadian database demonstrated a combined DVT/PE incidence of 122 per 100,000 for definite cases and 78 per 100,000 for probable DVT/PE cases from 2000 to 2009. ${ }^{10}$ An Australian national database found a PE admission rate of 53 per 100,000 in $2009 .{ }^{11}$ Given that the NIS database does not distinguish between definite and probable $\mathrm{PE}$, and it is limited to only hospitalized cases, we feel that our data yield similar results.

Despite an increased number of PE admissions, several markers of disease severity declined. Specifically, the proportion of patients meeting criteria for massive PE or needing mechanical ventilation decreased. The median hospital LOS decreased, suggesting that although patients were admitted, they were stable for discharge from the hospital sooner. Finally, all-cause hospital mortality rates decreased, further suggesting that the admitted patients did not have as severe disease. We hypothesize that the disproportionate increase in 
TABLE 3 ] Comorbid Conditions for Patients Hospitalized With PE From 2002 to 2012

\begin{tabular}{|c|c|c|c|c|c|c|c|c|c|c|c|c|c|}
\hline Year & $\begin{array}{c}\text { Malignancy, } \\
\%\end{array}$ & $\begin{array}{c}\text { Heart } \\
\text { Failure, \% }\end{array}$ & $\begin{array}{c}\text { Diabetes, } \\
\%\end{array}$ & $\begin{array}{c}\text { Hypertension, } \\
\%\end{array}$ & $\begin{array}{c}\text { Liver } \\
\text { Disease, } \\
\%\end{array}$ & $\begin{array}{l}\text { Obesity, } \\
\%\end{array}$ & $\begin{array}{c}\text { Coagulopathy, } \\
\%\end{array}$ & $\begin{array}{c}\text { Renal } \\
\text { Failure, } \\
\%\end{array}$ & $\begin{array}{l}\text { Neurologic } \\
\text { Disease, } \\
\%\end{array}$ & $\begin{array}{c}\text { Paralysis, } \\
\%\end{array}$ & $\begin{array}{c}\text { Peripheral } \\
\text { Vascular } \\
\text { Disease, \% }\end{array}$ & $\begin{array}{c}\text { Valvular } \\
\text { Heart } \\
\text { Disease, \% }\end{array}$ & $\begin{array}{c}\text { Chronic Lung } \\
\text { Disease, \% }\end{array}$ \\
\hline 2002 & 20.9 & 13.4 & 15.3 & 37.7 & 0.8 & 9.5 & 5.1 & 2.8 & 6.6 & 2.2 & 2.9 & 5.2 & 22.3 \\
\hline 2003 & 13.7 & 13.7 & 16.2 & 41.2 & 1.1 & 10.2 & 4.9 & 3.0 & 6.6 & 2.0 & 2.8 & 5.0 & 22.4 \\
\hline 2004 & 15.6 & 15.2 & 17.7 & 45.9 & 1.2 & 10.9 & 4.7 & 3.5 & 7.5 & 2.0 & 3.3 & 5.8 & 24.8 \\
\hline 2005 & 15.6 & 14.9 & 17.8 & 47.0 & 1.3 & 11.3 & 4.6 & 4.5 & 7.5 & 2.0 & 3.3 & 5.8 & 25.8 \\
\hline 2006 & 15.4 & 15.2 & 18.9 & 49.4 & 1.2 & 11.6 & 4.8 & 7.4 & 7.7 & 1.9 & 3.6 & 6.4 & 25.7 \\
\hline 2007 & 16.4 & 13.9 & 20.0 & 51.2 & 1.5 & 13.1 & 5.1 & 8.1 & 8.4 & 2.1 & 4.2 & 5.8 & 25.9 \\
\hline 2008 & 15.1 & 13.3 & 20.0 & 52.8 & 1.6 & 15.0 & 5.1 & 8.2 & 8.6 & 2.3 & $4 . \%$ & 5.5 & 25.4 \\
\hline 2009 & 14.6 & 12.9 & 20.9 & 54.1 & 1.8 & 16.6 & 5.9 & 9.0 & 8.1 & 2.3 & 4.5 & 5.6 & 24.8 \\
\hline 2010 & 14.4 & 13.0 & 20.8 & 55.6 & 2.0 & 17.2 & 6.3 & 9.3 & 8.3 & 2.2 & 4.5 & 5.4 & 24.4 \\
\hline 2011 & 14.4 & 13.6 & 21.6 & 56.4 & 2.0 & 18.7 & 6.6 & 10.0 & 8.5 & 2.3 & 4.7 & 5.8 & 25.0 \\
\hline 2012 & 14.5 & 12.4 & 21.7 & 57.4 & 2.2 & 19.6 & 6.6 & 10.3 & 8.2 & 2.0 & 4.8 & 5.5 & 24.9 \\
\hline Overall & 15.3 & 13.7 & 19.6 & 51.1 & 1.6 & 14.7 & 5.5 & 7.5 & 7.9 & 2.1 & 4.0 & 5.6 & 24.8 \\
\hline$P$ value & .080 & .070 & $<.001$ & $<.001$ & $<.001$ & $<.001$ & .001 & $<.001$ & .001 & .331 & $<.001$ & .638 & .132 \\
\hline$r^{2}$ & 0.302 & 0.319 & 0.949 & 0.944 & 0.974 & 0.966 & 0.754 & 0.928 & 0.726 & 0.105 & 0.949 & 0.026 & 0.233 \\
\hline
\end{tabular}


TABLE 4] Outcomes for Patients Hospitalized With PE From 1993 to 2012

\begin{tabular}{|c|c|c|c|c|c|c|c|c|c|c|c|}
\hline Year & $\begin{array}{l}\text { Median } \\
\text { LOS }\end{array}$ & LOS IQR & $\begin{array}{c}\text { Adjusted } \\
\text { Median } \\
\text { Charges, \$ }\end{array}$ & Charges, IQR, \$ & $\begin{array}{c}\text { Mechanical } \\
\text { Ventilation, \% }\end{array}$ & Lytics, \% & IVC Filters, \% & $\begin{array}{c}\text { Overall } \\
\text { Mortality } \\
\text { Rate, \% }\end{array}$ & $\begin{array}{c}\text { Deaths per } \\
100,000 \\
\text { Population }\end{array}$ & $\begin{array}{c}\text { Mortality for } \\
\text { Nonmassive } \\
\text { PE, \% }\end{array}$ & $\begin{array}{l}\text { Mortality for } \\
\text { Massive PE, \% }\end{array}$ \\
\hline 1993 & 8 & $6-11$ & 16,475 & $10,748-26,211$ & & & 9.0 & 7.1 & 1.6 & & \\
\hline 1994 & 7 & $5-10$ & 16,635 & $10,811-26,251$ & & & 10.0 & 7.9 & 1.9 & & \\
\hline 1995 & 7 & $5-10$ & 16,517 & $10,644-25,808$ & & & 11.7 & 7.4 & 2.0 & & \\
\hline 1996 & 7 & $5-9$ & 16,287 & $10,412-25,934$ & & & 11.8 & 7.4 & 1.9 & & \\
\hline 1997 & 6 & $5-9$ & 16,383 & $10,540-25,959$ & & & 12.4 & 7.6 & 1.9 & & \\
\hline 1998 & 6 & $5-9$ & 17,080 & $10,985-27,561$ & 4.9 & 0.3 & 13.3 & 7.6 & 2.1 & 5.1 & 51.9 \\
\hline 1999 & 6 & $4-8$ & 16,759 & $10,699-27,434$ & 5.1 & 1.8 & 13.6 & 7.4 & 2.2 & 4.9 & 51.8 \\
\hline 2000 & 6 & $4-8$ & 17,909 & $11,348-29,529$ & 4.2 & 1.7 & 13.2 & 6.8 & 2.1 & 4.6 & 51.4 \\
\hline 2001 & 6 & $4-8$ & 18,456 & $11,699-30,439$ & 4.6 & 1.7 & 13.6 & 6.6 & 2.3 & 4.2 & 51.4 \\
\hline 2002 & 6 & $4-8$ & 20,344 & $12,738-34,292$ & 4.4 & 1.7 & 14.7 & 5.7 & 2.2 & 3.5 & 48.1 \\
\hline 2003 & 6 & $4-8$ & 21,244 & $13,084-36,190$ & 4.4 & 1.9 & 14.3 & 5.4 & 2.3 & 3.3 & 46.4 \\
\hline 2004 & 5 & $4-8$ & 22,404 & $13,893-37,826$ & 4.4 & 1.8 & 14.8 & 5.4 & 2.3 & 3.2 & 47.2 \\
\hline 2005 & 5 & $4-8$ & 22,649 & $13,846-39,262$ & 4.5 & 1.6 & 14.7 & 4.9 & 2.3 & 2.8 & 43.9 \\
\hline 2006 & 5 & $3-8$ & 23,595 & $14,306-40,389$ & 4.5 & 1.8 & 15.2 & 4.6 & 2.4 & 2.6 & 42.6 \\
\hline 2007 & 5 & $3-7$ & 24,231 & $14,792-41,326$ & 4.3 & 1.8 & 14.8 & 4.3 & 2.4 & 2.4 & 43.3 \\
\hline 2008 & 5 & $3-7$ & 25,291 & $15,495-43,237$ & 4.2 & 2.0 & 14.9 & 4.1 & 2.5 & 2.3 & 42.4 \\
\hline 2009 & 5 & $3-7$ & 25,784 & $15,753-44,169$ & 4.2 & 2.3 & 14.9 & 3.7 & 2.3 & 1.9 & 40.6 \\
\hline 2010 & 5 & $3-7$ & 26,129 & $15,888-45,126$ & 4.1 & 2.5 & 13.8 & 3.5 & 2.3 & 1.7 & 38.8 \\
\hline 2011 & 5 & $3-7$ & 26,807 & $15,991-46,242$ & 4.1 & 2.4 & 12.8 & 3.6 & 2.4 & 1.8 & 40.8 \\
\hline 2012 & 4 & $3-6$ & 25,728 & $15,505-44,493$ & 3.7 & 2.4 & 11.4 & 3.2 & 2.1 & 1.6 & 39.1 \\
\hline Overall & 5 & $3-8$ & 18,481 & $10,900-32,747$ & 4.3 & 1.7 & 13.6 & 5.1 & & 2.7 & 44.0 \\
\hline$P$ value & $<.001$ & & $<.001$ & & $<.001$ & $<.001$ & .007 & $<.001$ & $<.001$ & $<.001$ & $<.001$ \\
\hline$r^{2}$ & 0.856 & & 0.940 & & 0.694 & 0.620 & 0.336 & 0.933 & 0.630 & 0.967 & 0.944 \\
\hline
\end{tabular}

IVC, inferior vena cava; LOS, length of stay. See Table 1 legend for expansion of other abbreviation. 


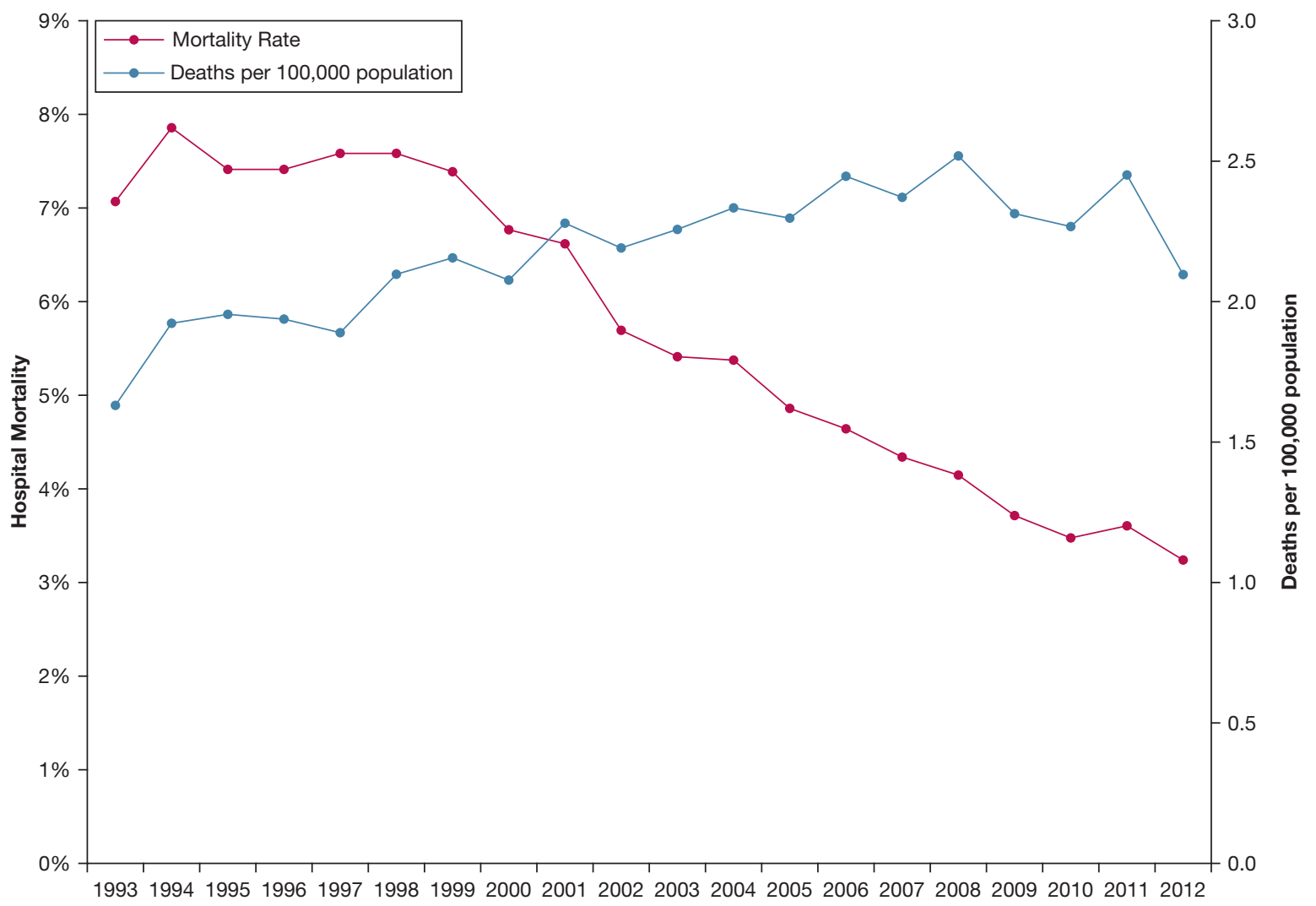

Figure 2 - All-cause hospital mortality for patients hospitalized with PE from 1993 to 2012. The all-cause hospital mortality rate for PE admissions significantly decreased; however, the population-adjusted number of deaths from hospitalizations for PE increased. See Figure 1 legend for expansion of abbreviation.

admission rates compared with disease severity may be related to the increased sensitivity and frequency of CTA, as opposed to a true increase in PE prevalence in the US population. CTA is now the most common modality for diagnosis; with its increased frequency and sensitivity, more PEs have been diagnosed. ${ }^{12-14}$ Wiener et $\mathrm{al}^{6}$ used the NIS to compare the frequency of PE admissions before and after widespread of CTA use in 1998. They found that the incidence of PE hospitalizations increased by $81 \%$ between two periods (1993-1998 vs 1998-2006), whereas case-fatality rates decreased by $36 \%$. Sheh et $\mathrm{al}^{15}$ reported similar results of increased PE diagnoses but decreased mortality, especially in those patients diagnosed by CTA compared with ventilation-perfusion scans. We agree with the conclusions of these prior studies that increased CTA use and sensitivity have resulted in more PE diagnoses and admissions. Our study is the first to use NIS to document the corresponding decrease in the frequency of pulmonary arteriography.

With more sensitive diagnostic testing, smaller PEs are now identified, although their clinical significance is sometimes unclear. ${ }^{16,17}$ A single-center study of 93 patients with isolated subsegmental PE showed $0 \%$ mortality and $1.1 \%$ recurrence rates at 3 months. ${ }^{18}$ We hypothesize that more subsegmental PEs were diagnosed over time, and because these are often associated with less severe disease, a disproportionate increase in subsegmental PE could have accounted for the decreases in disease severity despite increased total numbers of PE admissions.

Trends in short-term mortality rates for PE have led to significant speculation and discussion. In 1999, the Clinical Outcomes in the International Cooperative Pulmonary Embolism Registry (ICOPER; 2,454 patients in 52 European and North American hospitals) reported a 3-month mortality rate of $17.4 \% .{ }^{19}$ Subgroup analysis of their cohort found that mortality was $52.4 \%$ for massive PE but only $14.7 \%$ for nonmassive disease. ${ }^{20}$ The Multicenter Emergency Medicine Pulmonary Embolism in the Real World Registry (EMPEROR) of 1,880 patients in 22 EDs in the United States in 2011 reported a 30 -day mortality of $5.4 \% .{ }^{21}$ In a single-center study of 400 patients with PE in 2010, we reported a hospital mortality rate of $3.0 \% .^{22}$ In sum, these studies suggest a trend toward decreasing short-term mortality 


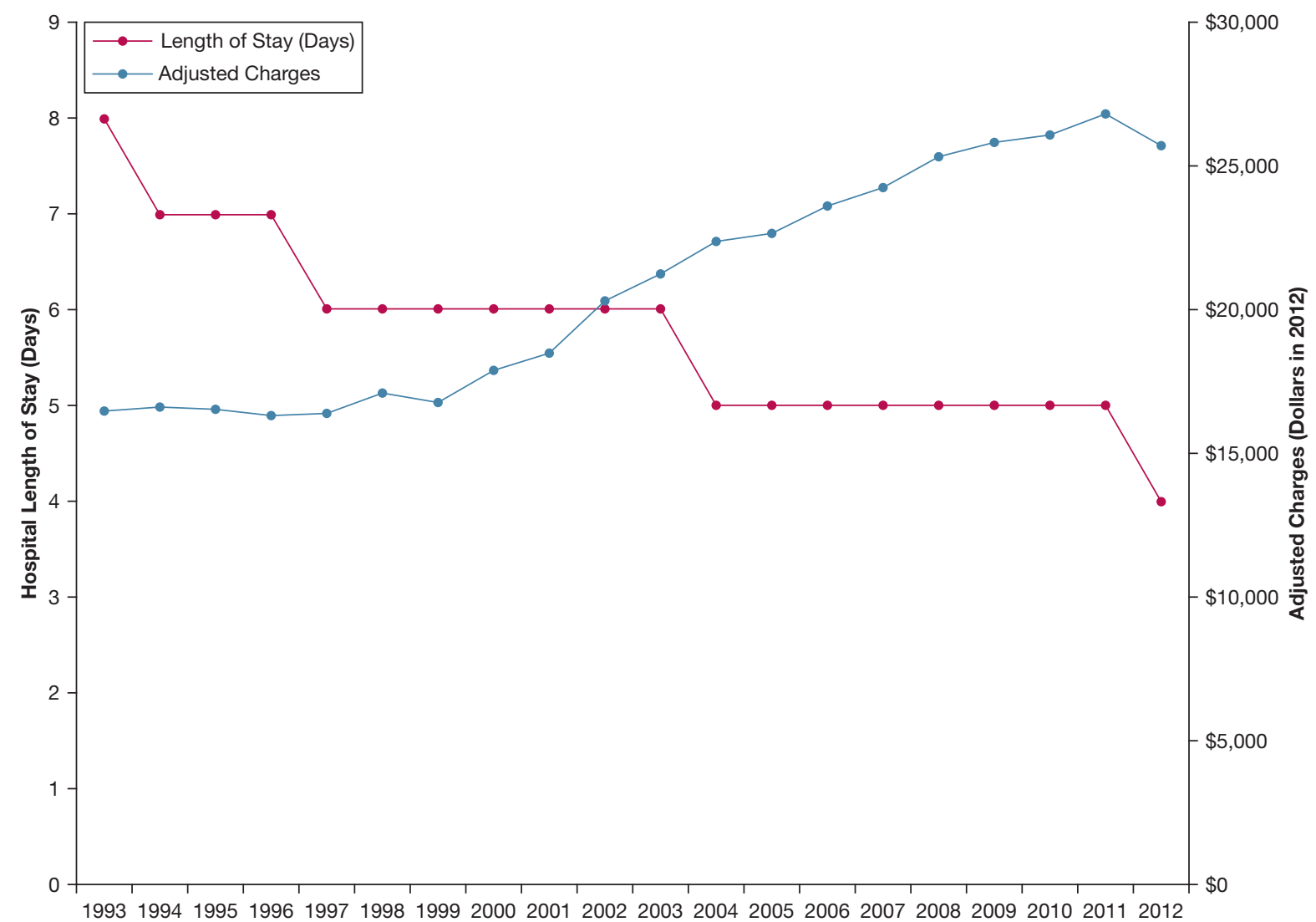

Figure 3 - Hospital length of stay and adjusted charges from 1993 to 2012. Length of stay significantly decreased; however, charges significantly increased.

for PE. The NIS does not provide posthospitalization data, and so 30-day and 3-month mortality rates for our cohort are unknown. However, we feel that the $3.2 \%$ all-cause hospital mortality rate in our 2012 NIS cohort confirms these trends.

Our results document a rise in the prevalence of cardiovascular comorbidities associated with PE requiring hospitalization (Table 3). National trends demonstrate a rise in prevalence of these comorbidities independent of PE. For example, projections show that by 2030 , the prevalence of hypertension will increase $7.2 \%$ from 2013 estimates. ${ }^{23,24}$ The total prevalence of diabetes in the United States is expected to more than double from 2005 to 2050 for all demographics. ${ }^{23,25}$ The prevalence of chronic kidney disease increased 10\% between assessment from between 1988 and 1994 and between 1999 and 2004, despite significant underdiagnosis of chronic kidney disease. ${ }^{23,26,27}$ The increasing prevalence of these comorbidities in PE patients may cause a rightward shift in pretest probability (ie, cardiovascular disease often confounds the evaluation of PE patients who present with chest pain and dyspnea). We suspect that such confounding may partially account for the rise in CTA testing. ${ }^{14}$

Because the NIS provides data on hospitalized patients only, the proportion of patients who presented with $\mathrm{PE}$ but were managed in the outpatient setting cannot be determined from this database. Data demonstrate that patients with low-risk PE can be safely managed as outpatients with low-molecular-weight heparins, and outpatient triage algorithms for low-risk PE diagnosed in ED patients have existed since the late 1990s. ${ }^{28-30}$ Our findings of increased admissions despite decreased severity suggest that outpatient management of low-risk $\mathrm{PE}$ is not yet the national practice. The frequency of CTA testing has increased in EDs, ${ }^{31}$ and we propose that further study could analyze national ED data to determine how increased rates of admission for PE compare with the utilization of outpatient management options for low-risk PE.

Stein and Matta ${ }^{4}$ identified 72,230 patients with PE in the NIS from 1999 to 2008 who had had a massive PE. Their cohort of massive PE patients was larger than ours 
(total massive PE 64,916 during that period), likely because of different inclusion criteria of PE and definition of shock. They report that $30 \%$ of their patients with massive $\mathrm{PE}$ received thrombolytic therapy, whereas we found a much lower rate $(8.3 \%$ for massive PE from 1998 to 2012). Despite methodological differences in population definitions, our analysis supports their conclusion that thrombolytic therapy is used in a surprising minority of massive PE patients. We did find an increase in thrombolytic therapy over time with a concurrent decrease in mortality for massive PE. Our data also support prior findings that the overall incidence of IVC filter placement increased during the past two decades, although we found a downward trend since 2006. ${ }^{32}$ As expected, we found that filters as well as thrombolytic therapy were more common in patients with massive PE. Stein et a ${ }^{33}$ used the NIS to demonstrate a similar association between filter placement and reduced mortality for patients with unstable PE, with or without thrombolytic therapy.

Fanikos et $\mathrm{al}^{34}$ reported that the median hospital cost was $\$ 8,764$ in their analysis of 991 patients hospitalized for PE at a single institution from 2003 to 2010. As expected, our data on hospital charges are higher when compared with their data on hospital costs. We feel that their analysis of a single institution is a more appropriate venue to consider actual costs because they were able to analyze the specific hospital aspects (eg, pharmacy, radiology, billing) that drive costs. However, our findings demonstrate that charges have increased despite decreasing LOS and mortality. If less severe PE cases are being admitted, then the dramatic increase in charges is all the more concerning regarding cost-efficient care. Increasing comorbidities may partially account for these charges, but a declining median age would argue that the increased charges are not simply reflective of an older, sicker population. We hypothesize that the increasing usage of CTA parallels an increase in resource use. Such an analysis is beyond the scope and capabilities of our analysis of NIS data. We suspect the increase in charges is not unique to PE but rather reflects national trends in health care. $^{35}$

\section{Limitations}

Our study is limited as a retrospective review of administrative data. We identified admissions within this database based upon hospital-reported ICD-9 coding rather than individual chart review. For admissions with a principal diagnosis of respiratory failure, our analyses relied upon the assumption that PE was a secondary diagnosis that directly contributed to the respiratory failure. We cannot absolutely determine the type of testing that yielded the diagnosis of $\mathrm{PE}$, and we cannot review the clinical data necessary to riskstratify the types of PE. Administrative comorbidity data likely underestimate the true prevalence of comorbid conditions. Mortality assessment is limited to all-cause hospital mortality, with an inability to determine whether deaths were related to cardiopulmonary failure as a direct result of PE or were related to other hospitalacquired events.

Our study demonstrates that more patients are being admitted for PE, but we cannot determine how this relates to the proportion of patients with $\mathrm{PE}$ managed in the outpatient setting. Further analysis of the Nationwide Emergency Department Sample from HCUP could help address this question.

\section{Conclusions}

We provide the largest presently available longitudinal, national analysis of PE admissions, demonstrating significant increases in admission rates and hospital charges despite decreases in the incidence of massive PE, hospital LOS, and mortality. The increase in populationadjusted admission rates has been disproportional to the incidence of severe PE. We hypothesize that these trends are related to the increased diagnostic sensitivity and frequency of CTA testing, resulting in more frequent diagnosis and admission of less severe PE. Diagnosis and admission decisions are complicated by an increased frequency of cardiovascular comorbidities, reflecting similar trends seen in other hospital admissions. With falling reimbursements and an aging population with increased cardiovascular comorbidities, the economics of providing cost-effective care to patients admitted with PE will likely remain challenging. 


\section{Acknowledgments}

Author contributions: S. B. S. had full access to all of the data in the study and takes responsibility for the integrity of the data and the accuracy of the data analysis. J. B. G.,

P. K., M. C., D. R. S., D. M. C., G. W. W., and R. G. W. contributed substantially to the study design, data analysis and interpretation, and the writing and critical review of the manuscript.

Financial/nonfinancial disclosures: The authors have reported to CHEST the following: D. M. C. has received payment for expert witness testimony related to the general standard care topic of detection and treatment of pulmonary embolism, and he has also worked on industry funded grants paid to his institution, with funds supporting research staff in the conduct of biomarker studies for detection of pulmonary embolism. None declared (S. B. S., J. B. G., P. K., M. C., D. R. S., G. W. W., R. G. W.).

Role of sponsors: The sponsor had no role in the design of the study, the collection and analysis of the data, or the preparation of the manuscript.

\section{References}

1. Geske JB, Smith SB, Morgenthaler TI, Mankad SV. Care of patients with acute pulmonary emboli: a clinical review with cardiovascular focus. Expert Rev Cardiovasc Ther. 2012;10(2):235-250.

2. Silverstein MD, Heit JA, Mohr DN, Petterson TM, O'Fallon WM, Melton LJ 3rd. Trends in the incidence of deep vein thrombosis and pulmonary embolism: a 25-year population-based study. Arch Intern Med. 1998;158(6):585-593.

3. Stein PD, Dalen JE, Matta F. Underuse of vena cava filters in unstable patients with acute pulmonary embolism. Am J Med. 2014;127(11):6.

4. Stein PD, Matta F. Thrombolytic therapy in unstable patients with acute pulmonary embolism: saves lives but underused. Am J Med. 2012;125(5):465-470.

5. Stein PD, Matta F. Vena cava filters in unstable elderly patients with acute pulmonary embolism. Am J Med. 2014;127(3):222-225.

6. Wiener RS, Schwartz LM, Woloshin S. Time trends in pulmonary embolism in the United States: evidence of overdiagnosis. Arch Intern Med. 2011;171(9):831-837.

7. The Web's Free 2015 Medical Coding Reference. http://www.icd9data.com. Accessed March 1, 2016.

8. US Census Bureau. US population by year. http://www.multpl.com/unitedstates-population/table. Accessed March $1,2016$.

9. Bureau of Labor Statistics. CPI inflation calculator. http://www.bls.gov/data/ inflation_calculator.htm. Accessed March 1, 2016.
10. Tagalakis V, Patenaude V, Kahn SR, Suissa S. Incidence of and mortality from Venous Thromboembolism in a RealWorld Population: the Q-VTE Study Cohort. Am JMed. 2013;126(9):832.e13-21.

11. Shiraev TP, Omari A, Rushworth RL. Trends in pulmonary embolism morbidity and mortality in Australia. Thromb Res. 2013;132(1):19-25.

12. Anderson DR, Kahn SR, Rodger MA, et al. Computed tomographic pulmonary angiography vs ventilation-perfusion lung scanning in patients with suspected pulmonary embolism: a randomized controlled trial. JAMA. 2007;298(23): 2743-2753.

13. Stein PD, Kayali F, Olson RE. Trends in the use of diagnostic imaging in patients hospitalized with acute pulmonary embolism. Am J Cardiol. 2004;93(10): 1316-1317.

14. DeMonaco NA, Dang Q, Kapoor WN, Ragni MV. Pulmonary embolism incidence is increasing with use of spiral computed tomography. Am J Med. 2008;121(7):611-617.

15. Sheh SH, Bellin E, Freeman KD, Haramati LB. Pulmonary embolism diagnosis and mortality with pulmonary CT angiography versus ventilationperfusion scintigraphy: evidence of overdiagnosis with CT? AJR Am J Roentgenol. 2012;198(6):1340-1345.

16. Carrier M, Righini M, Le Gal G. Symptomatic subsegmental pulmonary embolism: what is the next step? J Thromb Haemost. 2012;10(8):1486-1490.

17. Carrier M, Righini M, Wells PS, et al. Subsegmental pulmonary embolism diagnosed by computed tomography: incidence and clinical implications. A systematic review and meta-analysis of the management outcome studies. J Thromb Haemost. 2010;8(8):1716-1722.

18. Donato AA, Khoche S, Santora J, Wagner B. Clinical outcomes in patients with isolated subsegmental pulmonary emboli diagnosed by multidetector CT pulmonary angiography. Thromb Res. 2010;126(4):e266-e270.

19. Goldhaber SZ, Visani L, De Rosa M. Acute pulmonary embolism: clinical outcomes in the International Cooperative Pulmonary Embolism Registry (ICOPER). Lancet. 1999;353:1386-1389.

20. Kucher N, Rossi E, De Rosa M, Goldhaber SZ. Massive pulmonary embolism. Circulation. 2006;113(4):577-582.

21. Pollack CV, Schreiber D, Goldhaber SZ, et al. Clinical characteristics, management, and outcomes of patients diagnosed with acute pulmonary embolism in the emergency department: initial report of EMPEROR (Multicenter Emergency Medicine Pulmonary Embolism in the Real World Registry). J Am Coll Cardiol. 2011;57(6):700-706.

22. Smith SB, Geske JB, Maguire JM, Zane NA, Carter RE, Morgenthaler TI.
Early anticoagulation is associated with reduced mortality for acute pulmonary embolism. Chest. 2010;137(6):1382-1390.

23. Go AS, Mozaffarian D, Roger VL, et al. Heart disease and stroke statistics-2013 update: a report from the American Heart Association. Circulation. 2013;127(1): e6-e245.

24. Heidenreich PA, Trogdon JG, Khavjou OA, et al. Forecasting the future of cardiovascular disease in the United States: a policy statement from the American Heart Association. Circulation. 2011;123(8):933-944.

25. Narayan KM, Boyle JP, Geiss LS, Saaddine JB, Thompson TJ. Impact of recent increase in incidence on future diabetes burden: U.S., 2005-2050. Diabetes Care. 2006;29(9):2114-2116.

26. Levey AS, Coresh J, Balk E, et al. National Kidney Foundation practice guidelines for chronic kidney disease: evaluation, classification, and stratification. Ann Intern Med. 2003;139(2):137-147.

27. Coresh J, Selvin E, Stevens LA, et al. Prevalence of chronic kidney disease in the United States. JAMA. 2007;298(17): 2038-2047.

28. Piran S, Le Gal G, Wells PS, et al. Outpatient treatment of symptomatic pulmonary embolism: a systematic review and meta-analysis. Thromb Res. 2013;132(5):515-519.

29. Wells PS, Kovacs MJ, Bormanis J, et al. Expanding eligibility for outpatient treatment of deep venous thrombosis and pulmonary embolism with low-molecularweight heparin: a comparison of patient self-injection with homecare injection. Arch Intern Med. 1998;158(16):1809-1812.

30. Zondag W, Mos IC, Creemers-Schild D, et al. Outpatient treatment in patients with acute pulmonary embolism: the Hestia Study. J Thromb Haemost. 2011;9(8):1500-1507.

31. Feng LB, Pines JM, Yusuf HR, Grosse SD. U.S. trends in computed tomography use and diagnoses in emergency department visits by patients with symptoms suggestive of pulmonary embolism, 2001-2009. Acad Emerg Med. 2013;20(10): 1033-1040.

32. Stein PD, Kayali F, Olson RE. Twentyone-year trends in the use of inferior vena cava filters. Arch Intern Med. 2004;164(14):1541-1545.

33. Stein PD, Matta F, Keyes DC, Willyerd GL. Impact of vena cava filters on in-hospital case fatality rate from pulmonary embolism. Am J Med. 2012;125(5):478-484.

34. Fanikos J, Rao A, Seger AC, Cater D, Piazza G, Goldhaber SZ. Hospital costs of acute pulmonary embolism. Am J Med. 2013;126(2):127-132.

35. Healthcare Cost and Utilization Project. HCUP statistical briefs - costs \& charges. http://www.hcup-us.ahrq.gov/reports/ statbriefs/sb_costs.jsp. Accessed March 1, 2016. 